\title{
The Digital Transformation of Higher Education Teaching: Four Pedagogical Prescriptions to Move Active Learning Pedagogy Forward
}

\author{
Yngve Røe ${ }^{1 *}$, Slawomir Wojniusz ${ }^{1}$ and Annette Hessen Bjerke ${ }^{2}$ \\ ${ }^{1}$ Department of Physiotherapy, Oslo Metropolitan University, Oslo, Norway, ${ }^{2}$ Department of Primary and Secondary Teacher \\ Education, Oslo Metropolitan University, Oslo, Norway
}

Keywords: digital education, educational technology, pedagogy, blended learning, active learning pedagogy

\section{INTRODUCTION}

Digital learning technologies are expected to reform higher education: The recent Digital Education Action Plan (2021-2027) of the European Commission (EC) states that digital education should facilitate more personalised, flexible, and student-centred teaching (European Commission, 2021). This places great demands on university teachers, whose technological skills have long been considered the most formidable barrier to the digital transformation of higher education (Børte et al., 2020). Meanwhile, the COVID-19 pandemic has resulted in a steep technological learning curve among higher education teachers. Overnight, university teachers were forced to adapt their teaching to a digital, online format to meet the needs of more than 1.5 billion students across the globe who have been affected by COVID-19 restrictions (UNESCO, 2021). Despite a great willingness to change, over a year into the pandemic, the frustration among (university) teachers has become apparent. A United Kingdom survey found that higher education teachers thought that their pedagogical practis had been "reduced to the fulfilment of rudimentary technical functions" and that they played more of a transmissionist pedagogical role (Watermeyer et al., 2020). Taking the perspective of the students, recent survey data from Norwegian higher education shows that, during the pandemic, lack of motivation and sense of loneliness have been an increasing problem among students (NOKUT the Norwegian Agency for Quality Assurance in Education, 2020). From this we learn that a fully digital approach in higher education has limitations both when it comes to pedagogical practices and students' well-being.

A review of the literature in undergraduate science, engineering, and mathematics courses found that compared with traditional lecturing, active learning in combination with traditional lecturing, increases student performance and is therefore the preferred teaching practice in regular classrooms (Freeman et al., 2014). The same is true for higher education in general, where the literature broadly supports active, collaborative, cooperative, and problem-based teaching approaches (Prince, 2004). Despite this support, the adoption of active learning by higher education teachers has been contested for decades. A widely cited report on United States universities in the early 1990s concluded that the implementation of active student learning was obstructed by the powerful influence of educational tradition and a lack of coordinated institutional actions (Bonwell and Eison, 1991). It has been suggested that to promote active learning, institutions must take a more active role in changing teaching beliefs among academic staff (Antunes et al., 2021).

Despite the high expectations to digital education, a review commissioned by the Norwegian Ministry of Education and Research found that technology was most often used to support traditional teaching and that scholarly approaches that promote active pedagogies are lacking 
(Lillejord et al., 2018). An updated review by the same group concluded that staff's professional development is a prerequisite for successful implementation of technologies in active pedagogies (Børte et al., 2020).

Digital education is an umbrella term for various technologies and pedagogical practices in which online learning, distance learning, and blended learning are particularly highlighted in the EC action plan (European Commission, 2021). Blended learning designs combine digital technologies and face-to-face teaching, thus providing opportunities for social interaction between students and between teachers and students. Despite their popularity, the development of pedagogical elements in blended learning designs is anaemic. Perhaps as a result, the use of technology in higher education remains a divisive issue (Johnson et al., 2012; Lillejord et al., 2018).

The aim of this paper is to introduce four pedagogical prescriptions to move Active Digital Learning Pedagogy forward, to compile a list of barriers to the implementation of such a pedagogy, and to propose needed institutional actions to accelerate the implementation. Hence, this paper sets out to suggest directions for future empirical research that will add knowledge on which institutional actions are more important. We draw on the higher education literature and the authors' more than 50 years of teaching experience in health education and teacher education, in which we have conducted research on higher education teaching and supervision, including blended learning approaches. Although most examples provided herein are from Norwegian higher education, we believe that due to the extensive digitalisation of Norwegian society, the Norwegian context constitutes a pioneering and interesting case for other countries.

\section{THE ACTIVE DIGITAL LEARNING PEDAGOGY}

The EC's Digital Education Action Plan emphasises that digital technology is reshaping society and that it should offer personalised, flexible, student-centred, collaborative, and creative learning (European Commission, 2021). However, despite these high ambitions, studies suggest that technology is predominantly used to support existing educational practices (Damşa et al., 2015; Lillejord et al., 2018; García del Dujo and Martín-Lucas, 2020). Because classroom engagement is found to promote deeper levels of thinking and learning than traditional lectures (McGlynn, 2005), we suggest that the policy aims of digital education outlined in the EC plan can be fully achieved only when integrating digital technologies with active face-to-face learning (as in blended learning).

Active learning is a contested concept. A critical examination of its educational purposes found that it may be unfocused and unsettling, at times leaving students feeling "confused and (temporarily) incompetent" (Dall'Alba and Bengtsen, 2019). On the other hand, it has been shown to increase student performance (Freeman et al., 2014), and a classic review concluded that there is broad support for the core elements of active learning (Prince, 2004).
We draw on the work of Bonwell and Eison, who defined active learning as "instructional activities involving students in doing things and thinking about what they are doing" (Bonwell and Eison, 1991). Building on this and the EC's initiative to reset education for the digital age, we suggest that Active Digital Learning Pedagogy constitute four rudimentary pedagogical prescriptions on which we will embark below. Table 1 shows how these pedagogical prescriptions (given in the first row) map on to the EC's list of the advantages of digital technology in higher education.

Student-centredness is a multidimensional concept that encompasses the involvement of students in course decisions (including the selection of content and assessments), in the development of learning skills, and in shaping the (higher education) teacher's role (Lemos et al., 2014). The concept of student-centred learning has been linked to flexible, experiential, and self-directed learning (O'Neill and McMahon, 2005), which are clearly mapped on to the predicted outcomes of flexibility and creativity achieved through the introduction of digital technologies in higher education (European Commission, 2021). It has been argued that student-centred learning is about spaces that provide students with the opportunity to act upon their learning needs, intentions, and interests (Blackie et al., 2010; Damşa and Lange, 2019). To achieve this, students must engage with peers and teachers and work on meaningful tasks and projects, such as group discussions, and student meaning-making (Teo et al., 2008). Digital technologies offer such personalised, collaborative opportunities (European Commission, 2021).

Formative feedback constitutes the next pedagogical prescription on our list. Formative feedback means that learners make sense of information from various sources and that they use the information to enhance their learning strategies while integrating feedback into their learning processes (Carless and Boud, 2018). A literature review identified factors that influence students' use of teacher feedback: feedback must be specific, detailed, individualised, unauthoritative, and without an extensive use of academic terminology and jargon (Jonsson, 2012). Additionally, one must consider that students may lack strategies for productive use of feedback (Johansson et al., 2012). The five factors and the additional comment remind us that feedback is also about the receiver. A line of research has focused on developing students' feedback literacy, which entails appreciating feedback processes, developing the capacity to make judgements, managing affect, and taking action to use the feedback (Carless and Boud, 2018). It should also be noted that peer assessment as a formative practice has been found to be effective across a wide range of contexts (Double et al., 2020). However, although various models of formative feedback have been suggested across disciplines, none have been specifically proposed in a digital educational context (Steen-Utheim and Wittek, 2017; Tripodi et al., 2020). Besides in-person feedback, digital education offers unique opportunities for instant feedback by integrating it into the software. As an extension of these technological opportunities, we suggest that a collaborative, team-based working environment can offer a possibility of 
TABLE 1 | Pedagogical prescriptions for the Active Digital Learning Pedagogy, mapped on the advantages of implementing digital technologies as outlined by the EC.

\begin{tabular}{|c|c|c|c|c|}
\hline & Student-centredness & Formative feedback & Constructive alignment & Flexible infrastructure \\
\hline \multirow[t]{5}{*}{ Advantages of digital technologies } & Personalised & Personalised & & \\
\hline & Flexible & Flexible & & Flexible \\
\hline & Student-centred & Student-centred & Student-centred & \\
\hline & Collaborative & Collaborative & & Collaborative \\
\hline & Creative & & Creative & Creative \\
\hline
\end{tabular}

providing formative feedback. The relevance of the social learning environment in digital education is supported by findings showing that being committed to peers, being recognised, and feeling safe are conducive to learning in flipped classroom education (Steen-Utheim and Foldnes, 2018).

Although digital technologies in higher education have the potential to introduce new and more compound learning activities, they may alienate teachers and students from the learning process. The concept of Constructive Alignment arose from the seminal work of John Biggs (Biggs, 1996). "Constructive" refers to constructivism theory, while "Alignment" refers to a principle of curriculum theory emphasising that assessment tasks should be aligned with what is intended to be learned (Biggs, 1996). Alignment is achieved only by ensuring that the language terms used in the learning outcome descriptions are consistent with the educational and assessment methods. In educational interventions (such as those aimed at introducing digital technologies) designed to help students progress from lower-to higher-order learning skills, it is important that assessments reflect not only fact-based knowledge but also in-depth understanding. Although it can be argued that coherence is important for all types of teaching, in our experience, the use of digital technology in teaching without this in mind can easily lead to more fragmented learning processes. Moreover, empirical evidence suggests that teacher training programmes based on these principles result in more student-centred beliefs among participants (Warriem et al., 2014). Although it can be argued that constructive alignment is ideal for all types of teaching, we believe that in digital education, attention can easily be diverted towards the technology itself, thus alienating students from the learning process. We must remember that technology is not pedagogy.

Lastly, building on McGlynn. (2005) suggestion of classroom engagement, we suggest that learning should take place in a physical context that facilitates social interaction, variation, and (almost) unlimited digital access. Therefore, flexible infrastructure constitutes the last pedagogical prescription in our list. Our experience of giving far too many lectures in halls with fixed seats has taught us that learning spaces would benefit from flexible furnishing that can allow for different configurations adapted to the purpose at hand. Such flexible learning environments require a basic technological infrastructure.

While taking the EC's advantages of digital technologies as our point of departure when describing our four proposed pedagogical prerequisites, it should, however, be noted that none of them (the way they are described above) fully capture the "... and thinking about what they are doing" part of the definition put forward by Bonwell and Eison (Bonwell and Eison, 1991). As we read it, the concept of metacognition captures this important aspect. Metacognition was originally referred to as the knowledge about and regulation of one's cognitive activities in learning processes (Flavell, 1979), while more recent research makes a distinction between metacognitive knowledge and skills revealing ample evidence that metacognitive skills are an important predictor for learning (Veenman et al., 2006). A closer look at the body of research on student-centredness and formative feedback reveals that metacognition is an important feature both in student-centred learning [i.e., Lee and Hannafin (2016)], and when orchestrating formative feedback (Veenman et al., 2006). More research is needed to decide whether learning of metacognitive skills should be put forward as a separate pedagogical prescription in digital education.

The list of pedagogical prescriptions is obviously preliminary, inconclusive and needs to be further developed in a digital educational context. The slow adoption of digital pedagogies to date indicates that several factors in the educational context may hinder the promotion of Active Learning Pedagogy. These barriers are discussed in the next section.

\section{BARRIERS TO AN ACTIVE DIGITAL LEARNING PEDAGOGY}

A recent review found that teachers' conceptions of teaching, lack of digital competence, and added workload are among the barriers to the implementation of technology-supported education in general (Børte et al., 2020). The implementation of Active Digital Learning Pedagogy faces similar obstacles.

\section{Established Teaching Cultures}

A survey in Norwegian higher education found that teachers were generally rather positive about digital education but still sceptical of its benefits for their own disciplines (Kofoed et al., 2019). Evidence also suggests that teachers with a student-centred approach are more open to the use of purposeful technological tools in their teaching (Judson, 2006; Ertmer and OttenbreitLeftwich, 2010). In contrast to these teachers' more innovative approaches, teachers with a transmissionist focus tend to use technology as a supplementary tool (Damşa et al., 2015). Teachers play a decisive role in the digital transformation of higher education. Their autonomy allows them to choose their own teaching approaches, which in turn influence their contributions to long-term curriculum development. Consequently, teachers' 
individual beliefs about teaching and learning are crucially important, as underlined by a recent study on the attitudes of academic staff towards a pedagogic shift to active blended learning. Antunes, Armellini, and Howe (2021) identified four main categories of teachers in higher education: "active innovators," who believe that change is positive and apply it to their academic practice; "lagging innovators," who hold positive beliefs but fail to fully implement changes; "sceptical but obliging" teachers, who hold negative beliefs, but their practices are consistent with new approaches; and "sceptical and resistant" teachers, who hold negative beliefs and actively resist integrating new approaches into their practice. Without a significant share of "active innovators," the pace of pedagogic shifts in higher education will probably remain slow.

Another important but largely ignored point is that tensions can arise between existing teacher-centred cultures and the student-centredness of Active Digital Learning Pedagogy. A study conducted by our group on the experiences of health education teachers participating in blended learning found little evidence that the approach challenged their conceptions of teaching and learning (Røe et al., 2021). However, we suspect that there might be variations according to teachers' experience, age, and discipline. Evidence shows that experience is an important factor. A Swedish 10-year longitudinal study on teachers providing technology-supported education found that novice teachers initially had more teacher-focused conceptions but exhibited a faster and more profound shift towards studentcentred conceptions than more experienced colleagues (Englund et al., 2017).

\section{Lack of Digital Incentives and Legislation for Teachers}

Teachers' practical approaches to teaching tend to be heavily influenced by situational factors, the social teaching environment, and the discipline (Smeby, 1996; Richardson, 2005; LindblomYlänne et al., 2006). Institutional incentives and regulations can influence teachers' motivation to reform their teaching. Research shows that a lack of institutional support is the main cause of concern among teachers regarding the implementation of digital education (Wanner and Palmer, 2015). To our knowledge, few universities have developed incentive structures that capture unique aspects of digital education, such as the considerable additional workload in the design phase. Another reason that teachers may disfavour digital teaching is the current lack of clarity regarding digital material ownership. According to Norwegian law, traditional lectures are the property of the teacher, whereas the ownership of video lectures is disputed (Kielland, 2018). Due to this grey area, teachers face uncertainty regarding compensation for the reuse of digital material. We are concerned that this lack of legislation reduces teachers' motivation to participate in digital reform.

\section{Unequal Status of Education and Research}

In higher education, teaching and research are often equated and are considered to have mutual benefits. However, this widely publicised equality between the two is disrupted by structural discrepancies in their descriptions in policy documents. For example, the title of the recent digital strategy for Norwegian higher education reads "Innovative education and excellence in research" (UNIT, 2021). Considering that the lack of scholarly approaches is one of the challenges highlighted in a review of technology-supported education (Lillejord et al., 2018), we believe that excellence and quality in research and educational activities should be given equal weight.

Recent findings suggest that the role of research in education is contested and that teachers' teaching strategies uncritically draw on their personal preferences (Brew and Saunders, 2020). We are concerned that educational research efforts by teachers, are severely hampered by lack of support from institutional administration for this type of research.

\section{Inflexible Physical Learning Environment}

The extent to which the physical infrastructure at higher education institutions is adapted to modern perspectives of how learning should take place is questionable (Damşa et al., 2015; Børte et al., 2020). Despite a paucity of relevant research, evidence suggests that innovative, flexibly furnished technological classroom designs have a positive effect on teachers' choices of educational approaches (Siegel and Claydon, 2016). In our experience, access to flexibly furnished technological classrooms is limited. A reason for this may be that a considerable share of learning spaces is occupied by either lecture theatres or rooms with permanently installed equipment, limiting the applicability of Active Digital Learning Pedagogy.

Acknowledging these barriers, we suggest that a vigorous and more beneficial way forward is to reduce barriers by facilitating the prerequisites for Active Learning Pedagogy. Therefore, we end this section by presenting a list of steps that need to be taken for the "resetting of education and training for the digital age" (as worded in the EC's Digital Education Action Plan):

- Support student-centred teaching cultures.

- Introduce personalised digital incentive structures.

- Equate the status of research and teaching.

- Redesign the physical infrastructure.

With this list in mind, we propose actions to be taken by higher education institutions.

\section{NEEDED INSTITUTIONAL ACTIONS}

A recent study on active blended learning suggested that institutions aiming to promote large-scale sustainable change should actively promote changes in teaching practices and educational beliefs among teachers (Antunes et al., 2021). The same applies to technological skills. Børte et al. (2020) stress that there is an urgent need for more technological skills among higher education teachers. We strongly support this view. We believe that it is necessary for educational leaders at all levels to encourage reform in teaching, provide opportunities to increase teachers' technological skills, and confront established beliefs 
about education, especially those that are not supported by recent research.

It has been suggested that leadership responsibilities are more in the hands of institutional administration than academic leadership (Damşa et al., 2015). Therefore, increased attention to contextual factors may be required. An urgent step to be taken by institutions is to provide incentives for the compensation of teachers for digital development work and guarantee their ownership of video lectures and other digital material created without the direct involvement of institutional support functions. Reuse must be compensated for in a reasonable manner. Although this may be seen as costly in the short term, increased opportunities for the reuse of digital material may produce the opposite outcome. However, to take full advantage of such opportunities, educational leadership and planning across units and programmes are required.

Another issue is that good teaching practices are not being transferred to colleagues, nor do they change practices over time (Sinclair and Aho, 2018). The implementation of Active Learning Pedagogy should adopt a scientific approach, including dissemination in conferences and academic journals. To achieve this, both administrative support functions and educational research networks at institutions must be strengthened.

Good will and ambitious institutional strategies may not be enough. It is imperative that institutions take a holistic approach to educational quality and the design of the physical environment on campuses. In our experience, the design, maintenance, and rebuilding of learning spaces are often the responsibilities of separate institution departments. We believe that learning spaces designed for a particular pedagogy or practical skill should be kept to a minimum. The requirements for spaces suitable for Active Digital Learning Pedagogy should be met. Educational spaces that meet basic technological requirements (e.g., wallmounted monitors, wireless internet access, and power outlets for laptops) may offer better and longer-term solutions than advanced digital showroom prototypes. Based on observations at our university, pilot digital learning spaces that meet these

\section{REFERENCES}

Antunes, V. T., Armellini, A., and Howe, R. (2021). Beliefs and Engagement in an Institution-wide Pedagogic Shift. Teach. Higher Educ., 1-21. doi:10.1080/ 13562517.2021.1881773

Biggs, J. (1996). Enhancing Teaching through Constructive Alignment. High Educ. 32 (3), 347-364. doi:10.1007/BF00138871

Blackie, M. A. L., Case, J. M., and Jawitz, J. (2010). Student-centredness: the Link between Transforming Students and Transforming Ourselves. Teach. Higher Educ. 15 (6), 637-646. doi:10.1080/13562517.2010.491910

Bonwell, C. C., and Eison, J. A. (1991). Active Learning: Creating Excitement in the Classroom. 1991 ASHE-ERIC Higher Education Reports". Association for the Study of Higher EducationERIC Clearinghouse on Higher Education (Washington, D.C.Washington, DC: George Washington Univ.School of Education and Human Development).

Børte, K., Nesje, K., and Lillejord, S. (2020). Barriers to Student Active Learning in Higher Education. Teach. Higher Educ., 1-19. doi:10.1080/ 13562517.2020 .1839746 requirements have become immensely popular with teachers and students, even in after-work hours. We believe that this type of flexibly furnished digital learning spaces is the future.

\section{CONCLUDING REMARKS}

Significant pedagogical advancements in the use of digital technologies can be achieved only if higher education leaders and teachers pull in the same direction. Active Digital Learning Pedagogy and our suggested preliminary list of pedagogical prerequisites can provide insights into how to "pull" and in what direction. This unstructured literature review, informed by our own experiences as digital innovators, made us realise that the digital transformation of higher education can be far slower than desired, and is even at risk of maintaining at status quo. This is a problem: Higher education students of today are familiar with using digital technologies in their daily life and will increasingly expect educational practices that fully utilise the opportunities offered by digital learning technologies. There is a need for empirical research to investigate how our proposed pedagogical prescriptions for active digital pedagogy can move the digitalisation of higher education forward. In order to facilitate an Active Digital Learning Pedagogy, we propose that institutional actions must be taken.

\section{DATA AVAILABILITY STATEMENT}

The original contributions presented in the study are included in the article/Supplementary Material, further inquiries can be directed to the corresponding author.

\section{AUTHOR CONTRIBUTIONS}

YR was responsible for the planning of the paper. YR, SW, and $\mathrm{AB}$ participated in the writing of the paper.

Brew, A., and Saunders, C. (2020). Making Sense of Research-Based Learning in Teacher Education. Teach. Teach. Educ. 87, 102935. doi:10.1016/ j.tate.2019.102935

Carless, D., and Boud, D. (2018). The Development of Student Feedback Literacy: Enabling Uptake of Feedback. Assess. Eval. Higher Educ. 43 (8), 1315-1325. doi:10.1080/02602938.2018.1463354

Dall'Alba, G., and Bengtsen, S. (2019). Re-imagining Active Learning: Delving into Darkness. Educ. Philos. Theor. 51 (14), 1477-1489. doi:10.1080/ 00131857.2018.1561367

Damşa, C., de Lange, T., Elken, M., Esterhazy, R., Fossland, T., Frølich, N., et al. (2015). Quality in Norwegian Higher Education: A Review of Research on Aspects Affecting Student Learning. NIFU Report. Lysaker, Norway: Nordic Institute for Studies in Innovation Research and Education (NIFU).

Damşa, C., and Lange, T. d. (2019). Student-centred Learning Environments in Higher Education. Uniped 42 (1), 9-26. doi:10.18261/issn.1893-8981-2019-01-02

Double, K. S., McGrane, J. A., and Hopfenbeck, T. N. (2020). The Impact of Peer Assessment on Academic Performance: A Meta-Analysis of Control Group Studies. Educ. Psychol. Rev. 32 (2), 481-509. doi:10.1007/s10648019-09510-3 
Englund, C., Olofsson, A. D., and Price, L. (2017). Teaching with Technology in Higher Education: Understanding Conceptual Change and Development in Practice. Higher Educ. Res. Develop. 36 (1), 73-87. doi:10.1080/ 07294360.2016.1171300

Ertmer, P. A., and Ottenbreit-Leftwich, A. T. (2010). Teacher Technology Change. J. Res. Tech. Educ. 42 (3), 255-284. doi:10.1080/15391523.2010.10782551

European Commission (2021). Digital Education Action Plan (2021-2027): Resetting Education and Training for the Digital Age [Online]. Available: https://ec.europa.eu/education/education-in-the-eu/digital-education-actionplan_en (Accessed 08 27, 2021).

Flavell, J. H. (1979). Metacognition and Cognitive Monitoring: A New Area of Cognitive-Developmental Inquiry. Am. Psychol. 34 (10), 906-911. doi:10.1037/ 0003-066X.34.10.906

Freeman, S., Eddy, S. L., McDonough, M., Smith, M. K., Okoroafor, N., Jordt, H., et al. (2014). Active Learning Increases Student Performance in Science, Engineering, and Mathematics. Proc. Natl. Acad. Sci. U S A. 111 (23), 8410-8415. doi:10.1073/pnas.1319030111

García del Dujo, Á., and Martín-Lucas, J. (2020). "Towards 'Onlife' Education. How Technology Is Forcing Us to Rethink Pedagogy," in Blended Learning: Convergence between Technology and Pedagogy. Editor A. V. Martín-García (Cham: Springer International Publishing)), 1-19.

Johnson, T., Wisniewski, M., Kuhlemeyer, G., Isaacs, G., and Krzykowski, J. (2012). Technology Adoption in Higher Education: Overcoming Anxiety through Faculty Bootcamp. J. Asynchronous Learn. Netw. 16, 63-72. doi:10.24059/ olj.v16i2.240

Jonsson, A. (2012). Facilitating Productive Use of Feedback in Higher Education. Active Learn. Higher Educ. 14 (1), 63-76. doi:10.1177/1469787412467125

Judson, E. (2006). How Teachers Integrate Technology and Their Beliefs about Learning: Is There a Connection? J. Tech. Teach. Educ. 14, 581-597.

Kielland, T. (2018). Opphavsrettslige Problemstillinger Ved Digitalisering Av Undervisning Ved Universitet Og Høyskoler. Bergen: Universitetet i Bergen.

Kofoed, T., Wilhelmsen, J., and Ørnes, H. (2019). Digital Tilstand 2018. Perspektiver På Digitalisering for Laring I Høyere Utdanning. Editor R. Tungesvik. Norwegian Agency for International cooperation and Quality Enhancement in Higher Education.

Lemos, A. R., Sandars, J. E., Alves, P., and Costa, M. J. (2014). The Evaluation of Student-Centredness of Teaching and Learning: a New Mixed-Methods Approach. Int. J. Med. Educ. 5, 157-164. doi:10.5116/ijme.53cb.8f87

Lillejord, S., Børte, K., Nesje, K., and Ruud, E. (2018). Learning and Teaching with Technology in Higher Education - a Systematic Review. Oslo, Norway.

Lindblom-Ylänne, S., Trigwell, K., Nevgi, A., and Ashwin, P. (2006). How Approaches to Teaching Are Affected by Discipline and Teaching Context. Stud. Higher Educ. 31, 285-298. doi:10.1080/03075070600680539

McGlynn, A. P. (2005). Teaching Millennials, Our Newest Cultural Cohort. Educ. Dig. Essent. Readings Condensed Quick Rev. 71 (4), 12-16.

NOKUT the Norwegian Agency for Quality Assurance in Education (2020). Student Survey and Web portal [Online]. Available: https://www.nokut.no/ en/studiebarometeret/studiebarometeret/(Accessed December 17th, 2021).

O'Neill, G., and McMahon, T. (2005). "Student-centred Learning: What Does it Mean for Students and Lecturers?” in Emerging Issues in the Practice of university Learning and Teaching I (Dublin: AISHE)).

Prince, M. (2004). Does Active Learning Work? A Review of the Research. J. Eng. Educ. 93 (3), 223-231. doi:10.1002/j.2168-9830.2004.tb00809.x

Richardson, J. T. E. (2005). Students' Approaches to Learning and Teachers' Approaches to Teaching in Higher Education. Educ. Psychol. 25 (6), 673-680. doi:10.1080/01443410500344720

Røe, Y., Rowe, M., Ødegaard, N. B., and Dahl-Michelsen, T. (2021). Introducing Flipped Classroom Supervision: Challenging Physiotherapy Teachers' Beliefs about Teaching. Uniped 44 (4), 239-247. doi:10.18261/issn.1893-8981-202104-03
Siegel, C., and Claydon, J. (2016). Innovation in Higher Education: The Influence of Classroom Design and Instructional Technology. J. Sch. Educ. Tech. 12 (2Sept-Nov), 24-33.

Sinclair, J., and Aho, A.-M. (2018). Experts on Super Innovators: Understanding Staff Adoption of Learning Management Systems. Higher Educ. Res. Develop. 37 (1), 158-172. doi:10.1080/07294360.2017.1342609

Smeby, J.-C. (1996). Disciplinary Differences in University Teaching. Stud. High. Educ. 21 (1), 69-79. doi:10.1080/03075079612331381467

Steen-Utheim, A. T., and Foldnes, N. (2018). A Qualitative Investigation of Student Engagement in a Flipped Classroom. Teach. Higher Educ. 23 (3), 307-324. doi:10.1080/13562517.2017.1379481

Steen-Utheim, A., and Wittek, A. L. (2017). Dialogic Feedback and Potentialities for Student Learning. Learn. Cult. Soc. Interaction 15, 18-30. doi:10.1016/ j.lcsi.2017.06.002

Teo, T., Chai, C. S., Hung, D., and Lee, C. B. (2008). Beliefs about Teaching and Uses of Technology Among Pre-service Teachers. Asia-Pacific J. Teach. Educ. 36 (2), 163-174. doi:10.1080/13598660801971641

Tripodi, N., Feehan, J., Wospil, R., and Vaughan, B. (2020). Twelve Tips for Developing Feedback Literacy in Health Professions Learners. Med. Teach., 1-6. doi:10.1080/0142159x.2020.1839035

UNESCO (2021). COVID-19 Education Response. Available at: https://en. unesco.org/.

UNIT (2021). Innovativ Utdanning Og Fremragende Forskning. Digitaliseringsstrategi for Universitets- Og Høyskolesektoren (2021-2025) [Online]. Available at: https://documentcloud.adobe.com/link/review? uri=urn:aaid:scds:US:83d63ec0-3614-445d-bd6b-ebad2e5bbd29 (Accessed $0627,2021)$.

Veenman, M. V. J., Van Hout-Wolters, B. H. A. M., and Afflerbach, P. (2006). Metacognition and Learning: Conceptual and Methodological Considerations. Metacognition Learn. 1 (1), 3-14. doi:10.1007/S11409006-6893-0

Wanner, T., and Palmer, E. (2015). Personalising Learning: Exploring Student and Teacher Perceptions about Flexible Learning and Assessment in a Flipped university Course. Comput. Educ. 88, 354-369. doi:10.1016/ j.compedu.2015.07.008

Warriem, J., Murthy, S., and Iyer, S. (2014). A2I: A Model for Teacher Training in Constructive Alignment for Use of ICT in Engineering Education. Proc. 22nd Int. Conf. Comput. Educ. ICCE, 896-902.

Watermeyer, R., Crick, T., Knight, C., and Goodall, J. (2020). COVID-19 and Digital Disruption in UK Universities: Afflictions and Affordances of Emergency Online Migration. High Educ. (Dordr), 1-19. doi:10.1007/ s10734-020-00561-y

Conflict of Interest: The authors declare that the research was conducted in the absence of any commercial or financial relationships that could be construed as a potential conflict of interest.

Publisher's Note: All claims expressed in this article are solely those of the authors and do not necessarily represent those of their affiliated organizations, or those of the publisher, the editors and the reviewers. Any product that may be evaluated in this article, or claim that may be made by its manufacturer, is not guaranteed or endorsed by the publisher.

Copyright (C) 2022 Røe, Wojniusz and Bjerke. This is an open-access article distributed under the terms of the Creative Commons Attribution License (CC $B Y$ ). The use, distribution or reproduction in other forums is permitted, provided the original author(s) and the copyright owner(s) are credited and that the original publication in this journal is cited, in accordance with accepted academic practice. No use, distribution or reproduction is permitted which does not comply with these terms. 